\title{
The Crystal Structure of $M-\mathrm{SbOF}$
}

\author{
A NDERS ÅTRöM \\ Division of Inorganic Chemistry 2, Chemical Center, The Lund Institute of Technology, \\ Box 740, S-220 07 Lund 7, Sweden
}

\begin{abstract}
$M$-SbOF is orthorhombic, space group Pbca (No. 61), with $a=$ 11.673(1) $\AA, b=5.587(1) \AA, c=12.267(1) \AA$. Three oxygen and one fluorine atoms are bonded to $\mathrm{Sb}^{3+}$, all to one side, and such polyhedra form layers parallel to the $a b$ plane by corner and edge sharing. Evidence is given for an ordered arrangement of oxygen and fluorine anions. Relationships with other structures are described.
\end{abstract}

$\mathrm{F}$

our different forms of SbOF have previously been reported to exist. ${ }^{1}$ Two $F$ are orthorhombic, denoted $L$ - and $M$-SbOF, one is cubic and called $H$ SbOF. The fourth form is a glass. The structure of the $M$-form, stable at a somewhat higher temperature than the $L$-form, will be described here.

\section{EXPERIMENTAL}

$M$-SbOF could be prepared by heating $L$-SbOF in sealed gold capsules at temperatures of $220-260^{\circ} \mathrm{C}$ for a few hours, followed by quenching in ice water. $M$-SbOF could also be prepared by heating an equimolar mixture of $\mathrm{SbF}_{3}$ and $\mathrm{Sb}_{2} \mathrm{O}_{3}$ by the same technique. Rodshaped colourless crystals were obtained, and single crystal studies showed them to be of orthorhombic symmetry. Integrated intensity data were collected with a Weissenberg camera using $M o K \alpha$ radiation. The intensities of 709 reflexions were measured with a densitometer. Crystallographic constants for $M$-SbOF are given in Table 1 and a part of the indexed Hägg-Guinier powder pattern in Table 2. The calculation of the celldimensions was based on 45 indexed lines.

The following computer programs were used:

PIRUM. Cell parameters from powder data (P. E. Werner, Stockholm).

DRF. Data reduction and Fourier calculations (A. Zalkin, Berkeley, Calif.).

LALS. Full matrix, least-squares calculations (A. Zalkin, Berkeley, Calif.).

DISTAN. Calculation of distances and angles (A. Zalkin, Berkeley, Calif.).

(All programs modified for the UNIVAC 1108 Computer in Lund.)

Table 1. Crystallographic constants for $M$-SbOF.

Unit cell dimensions: $a=11.673(1) \AA$

$b=5.587(1) \AA$

$c=12.267(1) \AA$

Space group $\mathrm{Pbca}$, No. 61

$Z=16, V=800.0(2) \AA^{3}$

Acta Chem. Scand. 26 (1972) No. 10 
Table 2. Part of a Hägg-Guinier powder pattern of $M-\mathrm{SbOF}\left(\mathrm{Cu} K \alpha_{1}\right.$ radiation).

\begin{tabular}{lccc}
\hline$I_{\text {obs }}$ & $\sin ^{2} \theta_{\text {obs }}$ & $h k l$ & $\sin ^{2} \theta_{\text {calc }}$ \\
\hline $\mathrm{m}$ & .02014 & 102 & .02012 \\
$\mathrm{~m}$ & .02734 & 111 & .02730 \\
$\mathrm{vw}$ & .03326 & 202 & .03319 \\
$\mathrm{w}$ & .03912 & 112 & .03913 \\
$\mathrm{w}$ & .04035 & 211 & .04037 \\
$\mathrm{vst}$ & .05232 & 212 & .05219 \\
$\mathrm{w}$ & .05497 & 302 & .05496 \\
$\mathrm{w}$ & .06223 & 311 & .06214 \\
$\mathrm{w}$ & .06314 & 004 & .06308 \\
$\mathrm{w}$ & .06750 & 104 & .06743 \\
$\mathrm{~m}$ & .06972 & 400 & .06967 \\
$\mathrm{vw}$ & .07190 & 213 & .07191 \\
$\mathrm{w}$ & .07408 & 312 & .07397 \\
$\mathrm{~m}$ & .07610 & 020 & .07603 \\
\hline
\end{tabular}

\section{STRUCTURE DETERMINATION}

The determination of the structure was started by assuming that it belonged to the centrosymmetrical space group $\mathrm{Pbca}$ (No. 61). A three-dimensional Patterson function was calculated, and sixteen $\mathrm{Sb}$ atoms could be placed on the $8(c)$ positions. Their coordinates were refined by least-squares calculations, and a difference Fourier synthesis was then analyzed for unique peaks which could all be assigned as anions. The least-squares refinement, now including all anions assumed to be oxygens, also on $8(c)$ positions, with isotropic temperature factors for all atoms, converged to an $R$-index of 0.066 , using weights calculated by the program LALS according to Cruickshank. As the maximum absorption was found to be negligible, no absorption correction was made. A list of $F_{o}, F_{\mathrm{c}}$ is available on request to the author.

A ball-and-spoke model was built of the structure in order to study the polyhedra, i.e. the way they would join to form the structure, and also to learn if there were reasons to believe that the two different anions were ordered. Half of the anions $(2 \times 8)$ were found to be bonded to three cations, whereas the other half was only bonded to one cation. By using Pauling's

Table 3. $M$-SbOF. Atomic coordinates and thermal parameters. All atoms in $8(c)$. The expression for the anisotropic temperature factor is $\exp -\left(\beta_{11} h^{2}+\beta_{22} k^{2}+\beta_{33} l^{2}+2 \beta_{12} \mathrm{hk}+2 \beta_{13} \mathrm{hl}+2 \beta_{23} \mathrm{kl}\right)$.

\begin{tabular}{lllllllllll}
\hline & \multicolumn{1}{c}{$x$} & $y$ & $z$ & $B\left(\AA^{2}\right)$ & $\beta_{11}$ & $\beta_{22}$ & $\beta_{33}$ & $\beta_{12}$ & $\beta_{13}$ & $\beta_{23}$ \\
\hline $\mathrm{Sb}_{1}$ & $.1155(1)$ & $.2128(2)$ & $.0099(1)$ & $(1.09)$ & $.0025(1)$ & $.0072(33)$ & $.0018(1)$ & $.0005(3)$ & $-0.0000(1)$ & $.0005(2)$ \\
$\mathrm{Sb}_{2}$ & $.1442(1)$ & $.8099(2)$ & $.2080(1)$ & $(0.89)$ & $.0017(1)$ & $.0068(33)$ & $.0015(1)$ & $.0001(2)$ & $-0.0002(1)$ & $.0000(2)$ \\
$\mathrm{O}_{1}$ & $.0500(11)$ & $.9249(28)$ & $.0817(10)$ & $1.39(22)$ & & & & & \\
$\mathrm{O}_{2}$ & $.2622(10)$ & $.6228(30)$ & $.1241(9)$ & $1.07(21)$ & & & & & \\
$\mathrm{F}_{1}$ & $.0483(10)$ & $.5085(25)$ & $.1872(9)$ & $1.74(22)$ & & & & & \\
$\mathrm{F}_{2}$ & $.1969(10)$ & $.4925(24)$ & $.4070(9)$ & $1.72(22)$ & & & & & \\
\hline
\end{tabular}


second principle ${ }^{2}$ for these four different positions, $\sum S_{i}$ was found to be 2.25 for 16 anions, each bonded to three cations, and 0.75 for 16 anions, each bonded to one cation. Oxygens and fluorines were thus ordered according to this scheme, and a new least-squares refinement, including anisotropic temperature factors for $\mathrm{Sb}$-atoms, reduced the $R$-index to $5.3 \%$. Atomic parameters are given in Table 3, and distances are given in Fig. 2.

\section{DESCRIPTION OF THE STRUCTURE}

The structure of $M$-SbOF is projected down the $b$-axis in Fig. 1, as a balland-spoke drawing. The two crystallographically different $\mathrm{Sb}$-atoms are each surrounded by three oxygens and one fluorine, as shown in Fig. 2, all to one side of the cation so that the same configuration is obtained in this case as that

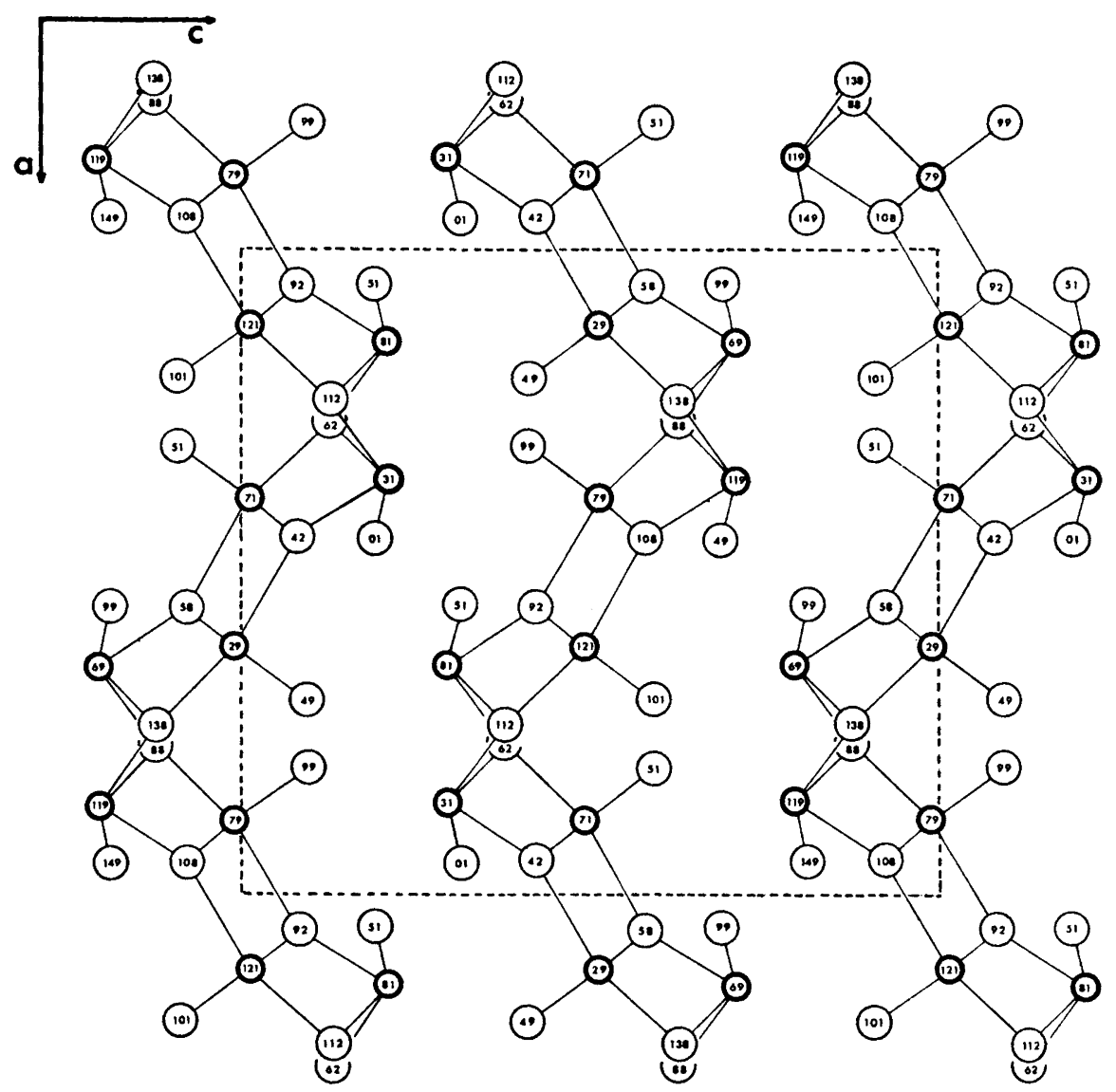

Fig. 1. The crystal structure of $M$-SbOF, projected down the $b$-axis. The heavier circles represent $\mathrm{Sb}$ atoms. Figures are in hundredths of the $b$-axis.

Acta Chem. Scand. 26 (1972) No. 10 

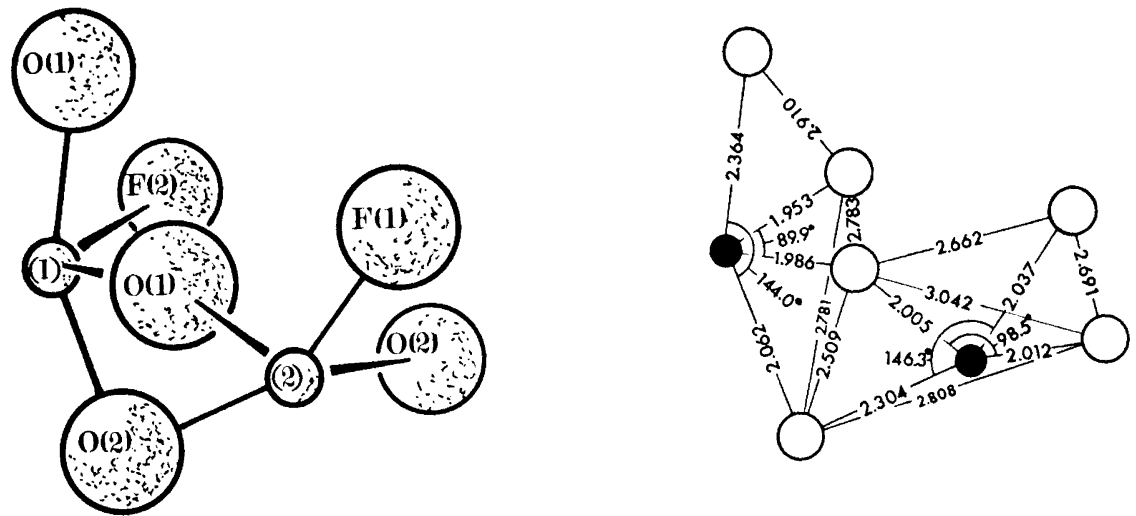

Fig. 2. Clinographic projection of a part of the SbOF layer. In the right part angles and distances are indicated. S.D. for angles are $\pm .5^{\circ}$, for cation-anion distances $\pm .01 \AA$, for anion-anion distances $\pm .02 \AA$.

observed for $L$-SbOF., ${ }^{1}$ These two $\mathrm{SbO}_{3} \mathrm{~F}$ polyhedra share edges in a different way than the polyhedra in $L$-SbOF, but such a unit of two $\mathrm{SbO}_{3} \mathrm{~F}$ polyhedra described in Fig. 2 edgeshare over a centre of symmetry by the same kind of edgesharing that occurs in $L$-SbOF.

In the two kinds of edgesharing that exist in $M-\mathrm{SbOF}$, one equatorial anion is left to be one of the terminal fluorines belonging to one of the two $\mathrm{Sb}$ atoms; the other terminal fluorine is in an axial position bonded to the other $\mathrm{Sb}$ atom. It is then easy to understand why these two antimony-fluorine distances are different. It has been shown ${ }^{4}$ that the geometry of this $\mathrm{SbX}_{4}$ polyhedron can be seen as the result of simple packing of anions and the lone pair attached to the antimony atom. The lone pair forms the third corner in an equatorial triangle, and with the other axial anions the polyhedron is a trigonal bipyramid. The axial cation-anion distances are for geometrical reasons somewhat larger than the equatorial cation - anion distances. ${ }^{4}$

The distances in the two different $\mathrm{SbO}_{3} \mathrm{~F}$ polyhedra that exist in $M$-SbOF are compared in Table 4 with the calculated distances in the ideal model

Table 4. $\mathrm{d}_{1}$ and $\beta$ are equatorial distance and angle, respectively. $\mathrm{d}_{2}$ and $\alpha$ are axial distance and angle, respectively. Calculated values are according to the close packed model given in Ref. 4.

\begin{tabular}{|c|c|c|c|c|c|c|}
\hline & $\begin{array}{c}\text { Fluoride } \\
\text { calc. }\end{array}$ & $\begin{array}{l}\text { Oxide } \\
\text { calc. }\end{array}$ & & $\begin{array}{l}\mathrm{Sb}(1) \\
\text { obs. }\end{array}$ & & $\begin{array}{c}\mathrm{Sb}(2) \\
\text { obs. }\end{array}$ \\
\hline$d_{1}$ & 1.91 & 2.00 & $\begin{array}{l}1.953 \\
1.986\end{array}$ & $\begin{array}{l}3(\mathrm{Sb}-\mathrm{O}) \\
3(\mathrm{Sb}-\mathrm{F})\end{array}$ & 2.01 & $\begin{array}{l}\text { (Sb-O, } \\
\text { average) }\end{array}$ \\
\hline$d_{2}$ & 2.14 & 2.27 & 2.22 & $\begin{array}{l}\text { (Sb-O', } \\
\text { average) }\end{array}$ & $\begin{array}{l}2.304 \\
2.037\end{array}$ & $\begin{array}{l}(\mathrm{Sb}-\mathrm{O}) \\
7(\mathrm{Sb}-\mathrm{F})\end{array}$ \\
\hline $\begin{array}{l}\beta \\
\alpha\end{array}$ & $\begin{array}{r}91.3^{\circ} \\
150.2^{\circ}\end{array}$ & $\begin{array}{r}93.6^{\circ} \\
153.4^{\circ}\end{array}$ & $\begin{array}{c}89.89^{\circ} \\
144.03\end{array}$ & $\begin{array}{l}(F-S b-O) \\
(O-S b-O)\end{array}$ & $\begin{array}{l}98.45 \\
146.27\end{array}$ & $\begin{array}{l}(\mathrm{O}-\mathrm{Sb}-\mathrm{O}) \\
(\mathrm{F}-\mathrm{Sb}-\mathrm{O})\end{array}$ \\
\hline
\end{tabular}


derived from simple packing. ${ }^{4}$ The edgesharing naturally causes electrostatic distortions, but in spite of this the agreement is astonishingly good.

The nearest-neighbour cation-anion distances for $\mathrm{Sb}(1)$ are $3.19(1)$, $2.84(1)$, and $3.02(1) \AA$, respectively, and the corresponding figures for $\mathrm{Sb}(2)$ are $2.81(1), 3.08(1)$, and $3.23(1) \AA$, respectively. The shortest anion-anion distances are of course those forming the two kinds of edge-sharing; they are $2.47(3)$ and $2.51(2)$.

The unit described in Fig. 2 joins an identical unit by edge-sharing over a centre of symmetry so that a block consisting of $4 \mathrm{SbO}_{3} \mathrm{~F}$ polyhedra is formed. Such blocks join by corner-sharing to form layers parallel to the $a b$ plane, which is shown in the polyhedral drawing of Fig. 3.

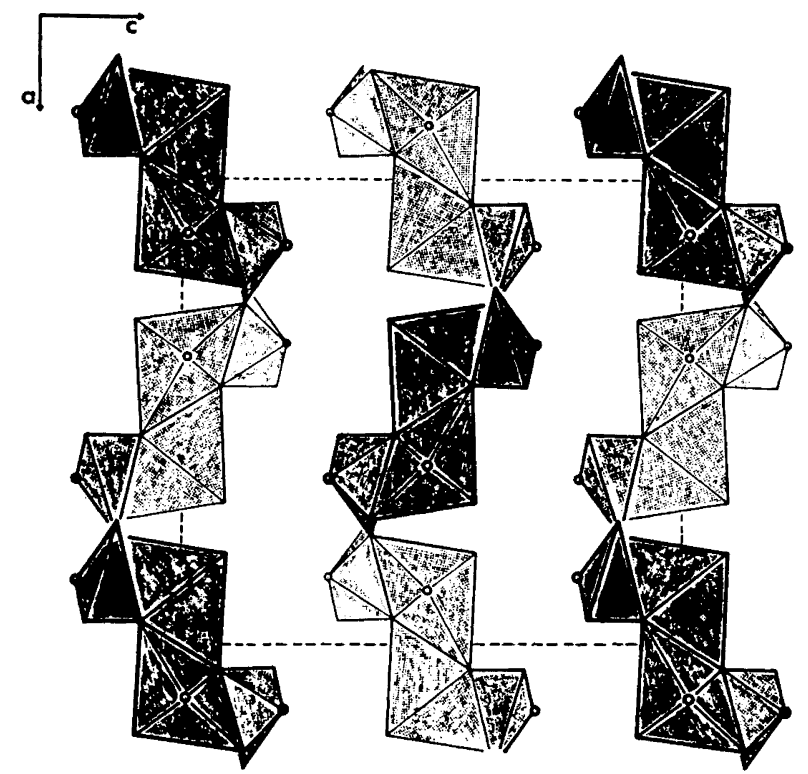

Fig. 3. $\mathrm{SbO}_{3} \mathrm{~F}$-polyhedra join by edge and corner sharing to form $\mathrm{SbOF}$ layers, parallel to the $a b$ plane.

It has been shown ${ }^{5}$ that a lone pair and its cation in oxides and oxide fluorides of $\mathrm{Sb}^{3+}, \mathrm{Pb}^{2+}$ and $\mathrm{Bi}^{3+}$ occupy the same volume as an anion does, and also that the centre of the volume of the lone pair is in a position corresponding to the centre of an anion. Looking down the $b$-axis of the ball-andspoke model built of the structure of $M$-SbOF, it was eye-catching the way atoms and lone pairs clustered in columns along $b$. When this observation was transformed into a drawing it became obvious that lone pairs and anions form the corners of slightly deformed pentagonal antiprisms, joined by the pentagonal faces along $b$. This is shown in Fig. 4. The prisms are bonded together in the $a b$-plane across $\mathrm{Sb}-\mathrm{O}$ bridges to form the SbOF layers. This is somewhat similar to the way boron icosahedra are held together by boron-boron bonds 


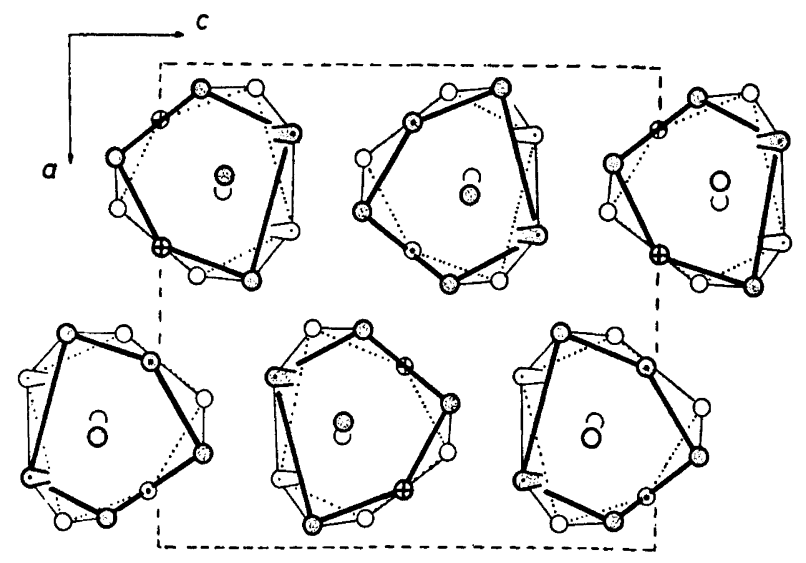

Fig. 4. Distorted pentagonal antiprisms of anions and lone pairs in $M \cdot \mathrm{SbOF}$. Heavily or lightly drawn anions and lone pairs are approximately $b / 2$ apart. The pear-shaped figures are lone pairs, parallel to the plane of the paper. Circles with crosses inside are lone pairs pointing downwards; circles with dots inside are lone pairs pointing upwards. The remaining circles are oxygen or fluorine.

in the structure of the element boron. ${ }^{6}$ No other comparison is implied; the description of the antiprisms in the structure of $M$-SbOF is made only in order to demonstrate the stereochemical effect of the lone pair.

Acknowledgements. The author thanks Professor Bengt Aurivillius and Dr. Sten Andersson for helpful discussions. He is also grateful to Dr. Karin Aurivillius for valuable comments on the manuscript and to the Computer Division of the National Rationalization Agency for the use of the Univac 1108 Computer in Lund.

This investigation forms a part of a research program sponsored by the Swedish Natural Science Research Council.

\section{REFERENCES}

1. Åström, A. and Andersson, S. Acta Chem. Scand. 25 (1971) 1519.

2. Pauling, L. J. Am. Chem. Soc. 51 (1929) 1010.

3. Aström, A. and Andersson, S. J. Solid State Chem. In press.

4. Andersson, S., Åström, A., Galy, J. and Meunier, G. J. Solid State Chem. In press.

5. Andersson, S. and Aström, A. NBS Special Publication 364, Solid State Chemistry, Proceedings of 5th Materials Research Symposium, July 1972.

6. Hoard, J. L., Hughes, R. E. and Sands, D. E. J. Am. Chem. Soc. 80 (1958) 4507.

Received April 28, 1972. 